\title{
The Wage Performance of Immigrant Women: \\ Full-Time Jobs, Part-Time Jobs, and the Role of Selection
}

\author{
Christian Dustmann \\ University College London, IZA (Bonn) and CEPR (London) \\ and
}

Christoph M. Schmidt

University of Heidelberg, IZA (Bonn), and CEPR (London)

October 2000

\begin{abstract}
This paper contrasts labour participation behaviour and wages of native and immigrant women. Since the impact of family structure on labor supply differs between natives and immigrants, we explicitly distinguish between part-time and full-time jobs. The choice of jobs is accounted for by an ordered probit selection model with an incidental threshold, thus offering a flexible strategy to address selection issues in a segmented labour market. Our analysis is based on panel data, allowing us to control for correlated individual-specific effects in both selection- and wage equations. We conclude that migrant women receive lower wages than native women in the same labor market segment, and that this is mainly associated with their relatively low educational endowments. Their relatively high ability to combine full-time work and child rearing somewhat mitigates these disadvantages.
\end{abstract}

JEL classification: J31, J22, J61.

Key words: Assimilation, Segmented Labour Markets, Discrete Choice Models.

We are grateful for comments by Barry Chiswick, John Haisken-De New and Frank Windmeyer, for research assistance by Boris Augurzky and Manuel Frondel, and for the hospitality of the IZA (Bonn). Correspondence to: Christian Dustmann, University College London, Dept. of Economics, Gower Street, London WC1E 6BT, UK (email: c.dustmann@ucl.ac.uk). 


\section{Non-Technical Abstract.}

A considerable part of the female labour force in the more developed economies are immigrant women, but migration research tends to concentrate, with few exceptions, on male migrants. In addition, where female labour market behaviour is at issue, studies often exclude immigrant women or do not allow for different behavioural patterns between native and migrant women. However, the residential and labour supply decisions of foreign-born females are typically residual to those of their husbands, and consequently they seem to work disproportionately often in low-quality jobs.

By contrast to the analysis of male migrants, participation issues present a formidable obstacle to direct wage comparisons between immigrant and native women. Migrant women typically display lower education, have more children, and live in lower-income families. Furthermore, across native and migrant women the individual decision to participate and to accumulate human capital, may be affected to a different extent by underlying characteristics such as family formation and child care arrangements. Cultural differences may therefore lead to systematic differences in participation behaviour, even holding opportunity sets constant.

In this context, selectivity-corrected wage equations typically differ from uncorrected variants, emphasizing that selectivity issues should not be ignored in a comparative analysis of the wage performance of migrant and native women. Yet, the variegated participation patterns documented in the literature suggest that the consideration of selectivity issues has to go beyond the mere question of participation, since migrant women may select into different labour market segments as natives. In this paper, both the wages and labour force participation behaviour of female migrants are analyzed, and compared to those of native women.

The paper contributes to the literature on migrant females along several directions. 
Firstly, other than most studies in this field, we use data from a long panel. The panel structure allows us to control for individual-specific fixed effects in both participationand wage equations. Secondly, the analysis distinguishes between part-time and fulltime jobs. Previous authors have found considerable differences in wage offers between these two market segments. In fact, the joint modelling of participation and wages, as well as the distinction between part- and full-time jobs proves to be crucial for our understanding of wage patterns of foreign-born women. Results of the joint model are in stark contrast to those of simple OLS regressions. Furthermore, it reconciles some of the apparent contradictions raised in this literature with respect to female assimilation patterns.

Finally, we investigate return plans, and the role of the husband for participation behaviour and wage growth. Our findings are compatible with the idea that return plans may induce intertemporal substitution of labour supply, thus leading to an increase in participation while being abroad. Furthermore, our results indicate that the assimilation pattern and labor force participation behaviour of female immigrants is influenced by the husband. We find that wives with husbands who entered the host country earlier are on a lower wage profile, and have a lower participation probability. 


\section{Introduction}

For the receiving countries immigration can be an important source of labour supply, it can act as a demographic factor rejuvenating the population, and it can provide substantial talent and motivation in the formation of human capital. Yet, despite this potential, relatively little is known about substantial fractions of the immigrant labour force: a considerable part of the female labour force in the more developed economies are immigrant women, but migration research tends to concentrate, with few exceptions, on male migrants (e.g. CHISWICK 1978, BoRJAs 1987, and for migrants to Germany Dustmann 1993 and Schmidt 1997). In addition, where female labour market behaviour is at issue, studies often exclude immigrant women or do not allow for different behavioural patterns between native and migrant women (for Germany see the survey by Zimmermann 1993). However, the residential and labour supply decisions of foreign-born females are typically residual to those of their husbands, and consequently they seem to work disproportionately often in low-quality jobs.

Only few studies investigate the economic performance of female immigrants. LONG (1980) uses cross-sectional data from the 1970 U.S. census to analyze earnings assimilation. He concludes that upon arrival, immigrant women earn more than native women, but that this advantage declines over time. By contrast, CHISwICK (1980) finds an increase in female hourly earnings with years since migration, supporting the idea that immigrants accumulate country-specific skills after arrival (CHISWICK 1978). This view is corroborated by BLAU (1980) who analyses the earnings assimilation of female migrants to the US at the turn of the century. Following Borjas' (1987) criticism of cross-sectional assimilation studies, Field-HEndrey and BALKAN (1991) analyse 
both 1970 and 1980 census data and data from the Panel Study on Income Dynamics, also finding that female migrants face an initial disadvantage, but assimilate over time.

By contrast to the analysis of male migrants, participation issues present a formidable obstacle to direct wage comparisons between immigrant and native women. Migrant women typically display lower education, have more children, and live in lower-income families. Furthermore, across native and migrant women the individual decision to participate and to accumulate human capital, may be affected to a different extent by underlying characteristics such as family formation and child care arrangements. Cultural differences may therefore lead to systematic differences in participation behaviour, even holding opportunity sets constant. REIMERS (1985) analyzes the labor force participation of different ethnic groups in the US labour market, and concludes that differences in characteristics account for most of the observable differences in participation behaviour across ethnic groups (a similar argument is raised in a dynamic context by Duleep and SANDERs 1994). Moreover, she documents that the participation behaviour of immigrant women adjusts to that of natives in only a matter of several years, an observation which she attributes to cultural assimilation.

DuleEP and SANDERS (1993) demonstrate that the presence of adult relatives in the household increases the labor force participation rate of immigrant women with young children. Moreover, the link between the participation behaviour of female immigrants to decisions of other household members may also differ from that relevant for natives. DULEEP and SANDERS (1993) present evidence that women who migrated after marriage displayed a lower labor force participation rate than immigrant women who migrated prior to marriage. They also report the skill formation process of the husband to affect the participation behaviour of the wife. 
Reimers (1983) for ethnic-minority men and FIELD-Hendrey and BALKAN (1991) for immigrant women address selectivity issues in their analyses of wage differences. In these papers, a probit selection equation controls for the choice to participate in the labour force. In this context, selectivity-corrected wage equations typically differ from uncorrected variants, emphasizing that selectivity issues should not be ignored in a comparative analysis of the wage performance of migrant and native women. Yet, the variegated participation patterns documented in the literature suggest that the consideration of selectivity issues has to go beyond the mere question of participation, since migrant women may select into different labour market segments as natives. In this paper, both the wages and labour force participation behaviour of female migrants are analyzed, and compared to those of native women.

The paper contributes to the literature on migrant females along several directions. Firstly, other than most studies in this field, we use data from a long panel. The panel structure allows us to control for individual-specific fixed effects in both participationand wage equations. Our estimation strategy proceeds in two steps. In the first step, participation- and wage equations are estimated simultaneously for each period, using a flexible discrete choice model together with standard wage regressions. In the second step, we use minimum distance estimation to impose the restrictions suggested by our empirical model. We also do not simply impute labour market experience from age and years of schooling - this measure has often been criticised in the context of female wage regressions. Instead, we use a measure for the actual number of years of active participation in the labour market.

Secondly, the analysis distinguishes between part-time and full-time jobs. Previous authors have found considerable differences in wage offers between these two market 
segments (see e.g. Averett and Hotchkiss 1997, Ermisch and Wright 1993, NAKAmURA and NAKAmura 1983). Given the likely discrepancies in the proximate determinants of labour force participation behaviour, the selection into part-time and full-time jobs can therefore be expected to substantially affect the wage comparison between migrants and natives. In fact, the joint modeling of participation and wages, as well as the distinction between part- and full-time jobs proves to be crucial for our understanding of wage patterns of foreign-born women. Results of the joint model are in stark contrast to those of simple OLS regressions. Furthermore, it reconciles some of the apparent contradictions raised in this literature with respect to female assimilation patterns.

Finally, we investigate return plans, and the role of the husband for participation behaviour and wage growth. DuleEP and SANDERs (1993) have argued that women who anticipate to live permanently in the US should exhibit a higher participation rate. On the other hand, return plans may induce intertemporal substitution of labour supply, thus leading to an increase in participation while being abroad (DUSTMANN 1997). Our findings are compatible with an intertemporal substitution of labour. Furthermore, our results indicate that the assimilation pattern and labour force participation behaviour of female immigrants is influenced by the husband. Consistent with Duleep and SAnders (1993) we find that wives with husbands who entered the host country earlier are on a lower wage profile, and have a lower participation probability.

The structure of the paper is as follows. In the next section, we explain in detail our estimation strategy. Section 3 introduces the data, and the variables used for our analysis, and provides some descriptives on participation behaviour and wages for 
migrant and native women over the sample period. In sections 4 and 5 , we discuss the results of the participation and wage analyses. Finally, section 6 concludes.

\section{The Econometric Model}

In our empirical analysis, we compare the wages of native-born and foreign-born females, and relate them to their underlying individual characteristics. Returns to individual characteristics may vary substantially across labour market segments (see e.g. Ermisch and Wright 1993 or Averett and Hotchisiss 1997), most prominently because fixed costs of employment in the form of recruiting and training costs increase the hourly cost of a part-time worker. Furthermore, full-time jobs offer better opportunities for advancement, thereby making it easier to recruit high-quality workers. Finally, the distinct labour supply behaviour of part-time workers might award some monopsony power to employers. Therefore, we model wage determination in full-time and part-time work separately.

We estimate for each wave the choice of full-time participation, part-time participation, or non-participation jointly with the wage equations in full-time or part-time jobs. We then impose across-equation restrictions by using minimum distance esti-

mation (see Chamberlain 1984). We allow for individual-specific fixed effects in participation- and wage equation, which may be correlated with the model regressors. Following MundLaK (1978), we parameterise the fixed effects as a linear projection on the within-individual means of time varying regressors. Our estimator is similar to that suggested by WoOLDRIDGe (1995), except that it imposes joint (and not marginal) normality on the errors in selection- and wage equations. 
We distinguish individual-level wage equations for part-time and full-time workers to be

$$
\ln w_{i t}^{g}=Z_{i t}^{g \prime} \gamma^{g}+\alpha_{i}^{g}+\tau_{t}^{g}+u_{i t}^{g}
$$

where $g \in\{P, F\}$ indicates part-time and full-time work, respectively, $w_{i t}^{g}$ are hourly wages for individual $i$ in period $t$, and $Z_{i t}^{g}$ is a vector of underlying (time-variant and time-invariant) wage determinants with parameter vectors $\gamma^{g}$. The $\tau_{t}^{g}$ are macro shocks which will be captured by a series of unrestricted year effects. The $\alpha_{i}^{g}$ are unobserved individual-specific parameters which may reflect unobserved productivity components, and which are possibly correlated with some of the model regressors. Wage differences between native and migrant women may then be driven either by discrepancies in endowments $Z^{g}$, distinct coefficients $\gamma^{g}$, differences in individual-specific effects $\alpha^{g}$, or by discrepancies in the allocation to labour market segments.

For modelling the choice between non-participation, part-time work, or full-time work we use an ordered probit model. This is a direct extension to full-time and part-time jobs of the simple reduced-form model of labour participation where nonparticipation is regarded as a corner solution to the optimization problem of the individual. Discrete choice models have been used repeatedly in the literature to model the allocation to part-time and full-time jobs (see, for instance, ZABALZA ET AL. 1980, Nakamura and Nakamura 1983, Ilmakunnas and Pudney 1990, Ermisch and Wright 1993, and DuncAN and WeEKS 1997). Deviating from the standard formulation of an ordered probit model, however, we use a more flexible version where the threshold between full-time and part-time work is specified as a function of individual characteristics (see PrADHAN and VAN SoEst 1995, for an application).

More formally, suppose that the underlying latent variable $y_{i t}^{*}$ reflects the propensity 
of the individual to offer labour to the market in period $t$, and is a linear function of a vector of variables $X_{i t}$, with coefficient vector $\xi$ :

$$
y_{i t}^{*}=X_{i t}^{\prime} \xi+\eta_{i}+\kappa_{t}+\epsilon_{i t}
$$

where $\eta_{i}$ is an unobserved individual-specific component, $\kappa_{t}$ is a year effect, and $X_{i t}$ is a vector of variables determining participation. The variable $y_{i t}^{*}$ is not observed, but an observation rule defines an observed variable $y_{i t}$ representing the category into which $y_{i t}^{*}$ falls:

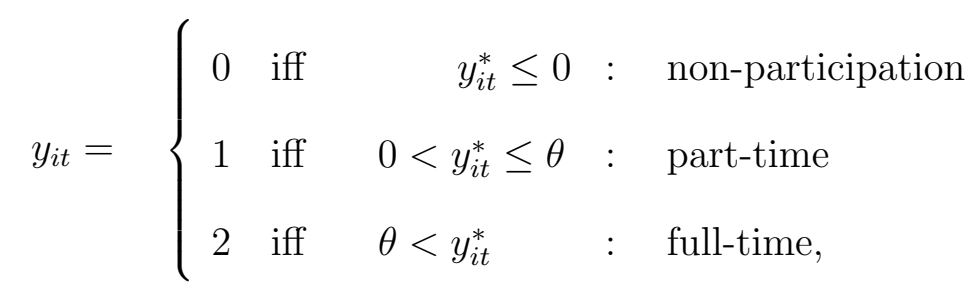

where 0 and $\theta$ are the relevant thresholds. The lower threshold of 0 is imposed as a normalization identifying the constant term in $X$, whereas the upper threshold $\theta$ is a parameter to be estimated. With a constant parameter $\theta$, though, the drawback of this model is its lack of flexibility: it imposes a strict order on the three choices. To obtain a more flexible selection rule, we parameterise $\theta$ to vary across individuals and across periods. Let the parameter $\theta_{i t}$ be a function of the vector $X_{i t}$ :

$$
\theta_{i t}=\exp \left(X_{i t}^{\prime} \beta\right)
$$

where $\beta$ is a vector of parameters and the exponential function is chosen to ensure that $\theta_{i t}$ does not become negative. In the ordered probit model with incidental threshold, all parameters are identified; it has as many parameters as the corresponding multino- 
mial model ${ }^{1}$. A direct interpretation of the parameter estimates is difficult, since the explanatory variables affect participation in either of the two regimes by shifting the latent variable, and by shifting the threshold. When we present the results of the participation equation, we report marginal effects of changes in variables on participation in full-time or part-time jobs, relative to non-participation; these effects are evaluated at average sample characteristics ${ }^{2}$.

Due to non-linearity, our complete three-equation model is parametrically identified. There are additional restrictions due to the exclusion of some components of $X_{i t}$ from the vector of wage determinants $Z_{i t}$. Moreover, a specific strategy is chosen to account for the presence of individual-specific unobserved heterogeneity in all three equations. Ordinary least squares (OLS) estimation of the wage equations (1) leads to consistent parameter estimates for part-time or full-time wage equations only if $\mathrm{E}\left(u_{i t}^{P}+\alpha_{i}^{P} \mid Z_{i t}^{P}, y_{i t}=1\right)=0$ or $\mathrm{E}\left(u_{i t}^{F}+\alpha_{i}^{F} \mid Z_{i t}^{F}, y_{i t}=2\right)=0$. Accordingly, if the individual-specific effects are correlated with the regressors, or if selection is non-random, OLS will lead to biased estimates. Furthermore, parameter estimates in the selection equation (2) will be biased if the $\eta_{i}$ are correlated with elements of the $X_{i t}$. Here we follow an approach suggested by Mundlak (1978) and Chamberlain (1984) and parameterise the individual-specific effects as a linear projection on the

\footnotetext{
${ }^{1}$ PrAdham and VAN SOEST (1995) show that for a similar application this extended version of the ordered probit model cannot be rejected against the multinomial logit model.

${ }^{2}$ In principle, standard errors can be computed by the Delta method, but this proves quite cumbersome for more complex likelihoods. Alternatively, one may calculate the standard errors by simulation. The standard errors we report for the marginal effects are computed from 500 random draws of the vector of parameters from the estimated asymptotic distribution of the vector of parameter estimates.
} 
mean of the time-variant variables ${ }^{3}$. We specify individual-specific effects as

$$
\alpha_{i}^{g}=\bar{Z}_{i}^{\prime} \pi^{g}+\nu_{i}^{g}
$$

and

$$
\eta_{i}=\bar{X}_{i}^{\prime} \rho+\omega_{i}
$$

where $\bar{Z}_{i}=\frac{1}{T_{i}} \sum_{t} \tilde{Z}_{i t}, \bar{X}_{i}=\frac{1}{T_{i}} \sum_{t} \tilde{X}_{i t}$, and $T_{i}$ are the number of periods an individual is observed in the panel, and $\tilde{Z}_{i t}$ and $\tilde{X}_{i t}$ are the time-variant variables in the wage equations and in the selection equation, respectively; $\nu_{i}^{g}$ and $\omega_{i}$ are the corresponding residual error terms.

Adding expressions (5) and (6) to the wage equations and to the selection equation, the composed error terms are given by $u_{i t}^{g}+\nu_{i}^{g}=\tilde{u}_{i t}^{g}$ and $\epsilon_{i t}+\omega_{i}=\tilde{\epsilon}_{i t}$. We assume that these errors are jointly trivariate normally distributed, with variances $\sigma_{u_{t}^{g}}^{2}$ and $\sigma_{\epsilon}^{2}=1$, and correlation coefficients $\rho_{\left(\epsilon u^{g}\right)_{t}}=\sigma_{\left(\epsilon u^{g}\right)_{t}} / \sigma_{u_{t}^{g}}$, where $\sigma_{\left(\epsilon u^{g}\right)_{t}}$ are the covariances between $\tilde{\epsilon_{i t}}$ and $\tilde{u}_{i t}^{g}$.

Having obtained the estimated parameter vectors for each time period, we combine these estimates, using minimum distance estimation. We use the optimal weighting matrix obtained from the first step estimates. Accordingly, the distance statistic is $\chi^{2}$-distributed under the null (that the restrictions are valid), with degrees of freedom equal to the number of restrictions imposed (see CHAMBERLAIN 1984 for details). In the specifications we report in the tables, we allow for time varying constant terms in selection- and wage equations. Furthermore, we allow the variances of the error terms in the wage equations to vary over time, and we impose no restrictions on $\operatorname{Cov}\left(\widetilde{u}_{i t}^{g}, \tilde{\epsilon}_{i t}\right)$.

\footnotetext{
${ }^{3}$ See WoOLDRIDGe (1995) for a similar formulation in panel data selection model.
} 


\section{Data and Variables}

The data used stems from the first 12 waves of the German Socio-Economic Panel (GSOEP), covering West Germany during the years 1984-1995. The GSOEP deliberately provides an oversampling of immigrants from five countries of origin, Greece, Italy, Spain, Turkey, and Yugoslavia ${ }^{4}$. This migrant sub-sample provides a comprehensive picture of the population of guest workers. These immigrants were actively recruited during the 1960s and the early 1970s, based on explicit recruitment treaties between Germany and potential sending countries in Southern Europe and Turkey. A substantial part of this immigrant population has remained in Germany until today.

From the overall data base, we construct a sample of 3841 native and 1073 foreignborn women who are cohabitating with their partners, and who are between 24 and 60 years old. We retrieve substantial background information from the database, like personal characteristics and the number of children in various age categories, and further add considerable information on the partner of the individual. Variable means over the entire sample period are reported for both sub-samples in Table $1^{5}$.

\footnotetext{
${ }^{4}$ The GSOEP distinguishes two sampling populations, individuals in households whose head is a native German, and individuals in household whose head is a foreigner from one of the five sending countries listed in the text. Due to the relative homogeneity of the immigrant population represented by the data, we do not investigate ethnic affiliation in detail.

${ }^{5}$ In Table A1 we report the number of individuals we observe in each of the 12 years (column 1), the number of participants (column 2), and the number of individuals reporting wages (column 3). There is clearly some panel attrition in both samples. In this study, we disregard any bias due to selective attrition. Table A2 documents the frequency of occurrence in the panel for both migrants and natives. The patterns are quite similar, with about 20 percent of individuals providing information in each of the 12 waves.
} 
Table 1: Descriptive Statistics

\begin{tabular}{|c|c|c|c|c|}
\hline \multirow[b]{2}{*}{ Variable } & \multicolumn{2}{|c|}{ Natives } & \multicolumn{2}{|c|}{ Migrants } \\
\hline & Mean & Std.Dev. & Mean & Std.Dev. \\
\hline \multicolumn{5}{|c|}{ Participation and Wages (1984 DM): } \\
\hline Participation & $50.12 \%$ & - & $48.84 \%$ & - \\
\hline Participation part-time & $28.76 \%$ & - & $12.12 \%$ & - \\
\hline Participation full-time & $21.36 \%$ & - & $36.72 \%$ & - \\
\hline Log hourly wage & 2.66 & 0.43 & 2.50 & 0.32 \\
\hline Median & 2.68 & - & 2.52 & - \\
\hline Log hourly wage, part-time & 2.58 & 0.47 & 2.43 & 0.40 \\
\hline Median & 2.59 & - & 2.44 & - \\
\hline Mean log hourly wage, full-time & 2.75 & 0.36 & 2.52 & 0.29 \\
\hline Median & 2.77 & - & 2.53 & - \\
\hline \multicolumn{5}{|l|}{ Individual Characteristics: } \\
\hline Education (years) & 10.92 & 2.02 & 8.92 & 1.92 \\
\hline Age & 42.66 & 9.77 & 41.99 & 9.07 \\
\hline Experience (years) & 13.41 & 9.78 & 12.41 & 1.06 \\
\hline Years of residence & - & - & 17.19 & 6.42 \\
\hline Intending to stay permanently & - & - & $29.13 \%$ & - \\
\hline \multicolumn{5}{|l|}{ Household Characteristics: } \\
\hline Household income (1984 DM) & 2945 & 1516 & 2518 & 1363 \\
\hline Number of children age $\leq 5$ & 0.28 & 0.60 & 0.32 & 0.61 \\
\hline Number of children age $>5$ & 0.52 & 0.78 & 0.86 & 0.98 \\
\hline Age, husband & 46.25 & 10.17 & 46.07 & 8.78 \\
\hline Years of residence, husband & - & - & 19.77 & 5.74 \\
\hline Husband arrived before & - & - & $65.45 \%$ & - \\
\hline Husband arrived after & - & - & $12.31 \%$ & - \\
\hline Husband intends to stay perm. & - & - & $30.27 \%$ & - \\
\hline Number of observations & \multicolumn{2}{|c|}{18152} & \multicolumn{2}{|c|}{7162} \\
\hline Number of individuals & \multicolumn{2}{|c|}{3841} & \multicolumn{2}{|c|}{1073} \\
\hline
\end{tabular}

Source: German Socio-Economic Panel GSOEP 1984-95. 
The overall labour force participation rate of foreign women is similar to that of native women. However, the majority of foreign-born female workers holds a full-time job, while nearly half of the female German workers are on part-time jobs. There is some discussion in the literature as to which definition should be used to distinguish between part-time and full-time workers. The data used in this analysis provides not only the hours the individual works, but also whether the individual considers the job as a part-time or a full-time occupation. We use these self-evaluations to discriminate between the two groups (see, e.g., Ermisch and Wright 1993).

Our primary variable of interest, the individual wage rate, is constructed as follows. Individuals report average normal weekly hours of work and actual hours of work (including overtime work, but excluding irregularities in hours worked due to illness etc.) for the month preceding the interview. Respondents also report gross monthly earnings in the month preceding the interview. Since reported monthly earnings include overtime payments, hourly earnings use effective number of hours worked. If the individual's actual number of hours worked is lower or equal to the normal number of hours worked, hours worked per month are simply normal hours worked, multiplied by 4.3. If, on the other hand, actual hours of work are higher than normal hours of work, and if, additionally, the individual reports that overtime work is paid for, then hours worked per month equal actual number of hours worked multiplied by 4.3 . It is these effective hours that we use in the construction of hourly wages; wages are expressed in real terms (1984 prices).

Averaging across labour market segments, wages are higher for native women. On average, native women receive higher wages than foreign women in both full-time and part-time, with a larger discrepancy for full-time wages. Furthermore, the standard 
deviation of wages is higher for natives irrespective of the labor market segment, indicating a more concentrated wage distribution for foreign-born individuals, while the wage distribution does not seem more skewed for either group of female workers. The large difference between full-time and part-time wages demonstrates that the distinction of full-time and part-time jobs is an essential element of the analysis. Native females also display substantially higher levels of school education than female immigrants, certainly accounting for some of the difference in average wages: According to our sample, on average, native females spend 2 years more in school.

Mean age is similar for the two subgroups, leading us to expect that, on average, natives command less work experience than migrants. Since females frequently exhibit interrupted work histories, this conclusion is not immediate, though. It has often been argued that potential experience is only an insufficient measure of work experience (e.g. ERMISCH and WRIGHT 1993). Here we use actual experience which is constructed in two stages. In the first stage, we record the individuals' labour market experience at entry into the panel, which is explicitly given in a biographical scheme. In the second stage, we complement this information for every year of panel participation by adding the number of months worked in the previous year; for each respondent, these are retrieved from an activity scheme to be filled in at every interview. Our experience variable refers therefore to the actual experience at the start of the current year.

Household characteristics might display a large impact on participation behaviour. Household income and fertility differences are the prime candidates for distinct behaviour of native and migrant women (recall that all women in the sample are married). Typically, an increase in other income leads to reducing labour supply via standard income effects. Other income (also in 1984 terms) amounts, on average, to 2945DM 
for German women, but to only 2518DM for foreign women ${ }^{6}$. Furthermore, child care responsibilities

deter from labour supply. The number of small children is somewhat higher among migrant women than among native females, while an even larger discrepancy is observed for children of school age. Therefore, the similar participation percentages of the two groups, despite these notable differences, indicate that either foreign women overcompensate the ensuing imbalance by a vastly different participation behaviour or - observationally equivalent given our data - that they have access to formal or informal child care arrangements facilitating more market hours. Likewise, foreign-born females may react less to changes in other income.

The migration history of both migrant women and their families indicates that many of the respondents arrived in Germany during the era of active guest worker recruitment until 1973. Two thirds of these women arrived after their husbands, and only approximately $20 \%$ arrived before their husbands. Nearly one third of the migrant women state that it is their intention to permanently stay in Germany, a figure which is almost identical with the share of husbands' responses to the same question (see below).

\subsection{Intertemporal Developments}

Figure 1 displays participation behaviour over the sample period. It reveals that, at the beginning of the sample period, participation rates (the sum of employment rates in

\footnotetext{
${ }^{6}$ The measure used for other income is the sum of husband's net income, rent income and income from property.
} 
full-time and part-time employment) of native and migrant women were almost identical, fluctuating in a nearly parallel fashion. From the early 1990s onwards, though, participation rates of natives and migrants diverged, with those of immigrants slightly decreasing. These patterns are consistent with the macroeconomic situation in Germany which was characterised by a serious recession starting in the early- to mid-1990s, and an accompanying sharp rise in unemployment figures. Figure 1 seems to suggest that migrants have reacted more sensitively to the economic downturn, indicating that they are employed in less stable jobs than natives.

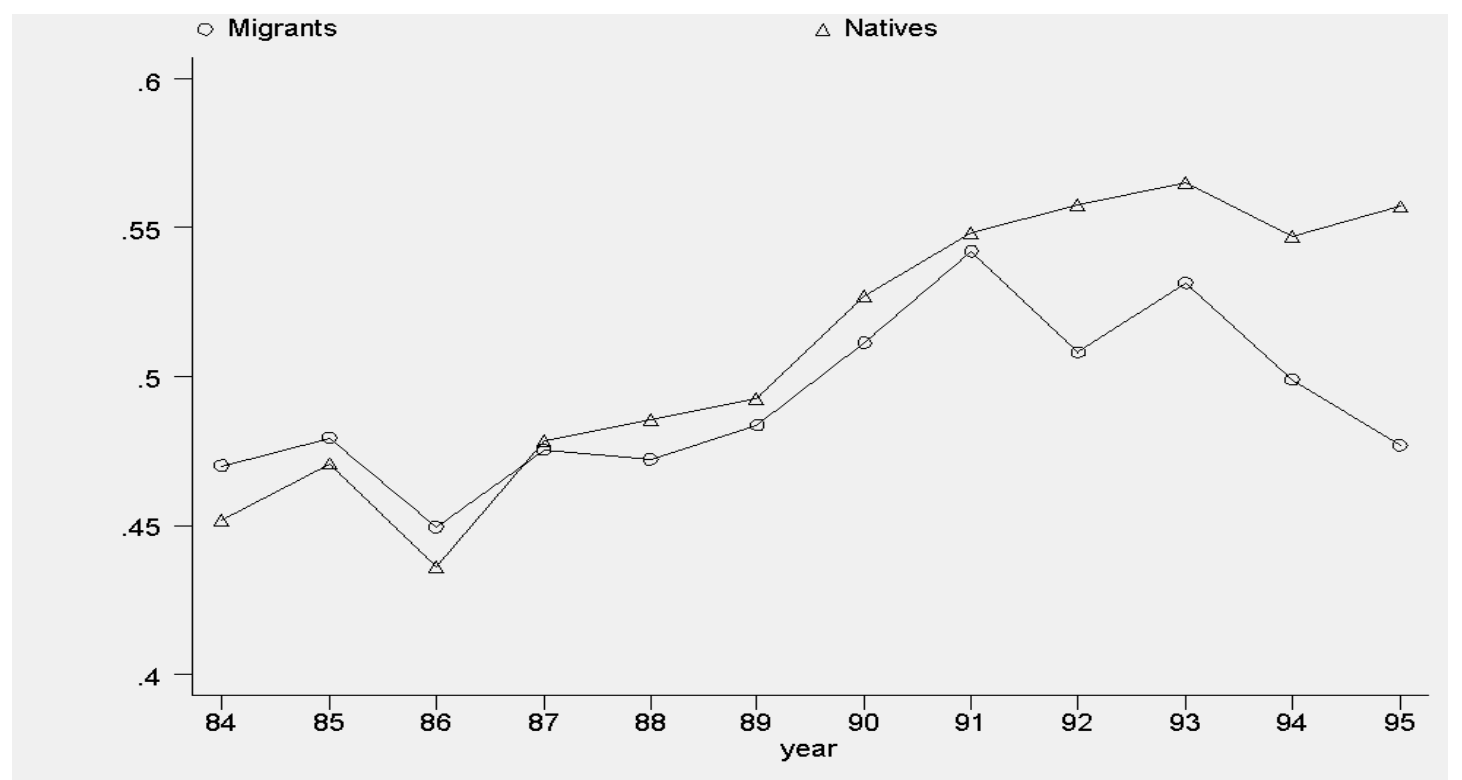

Figure 1: Female Labour Market Participation, 1984-1995

Real wages have been increasing over time, with wages of immigrants being lower than those of natives in both labour market segments. Unconditional differences may not reflect relative wages appropriately, though. To account for differences in education and labour market experience, we estimate regressions where we condition on year 
dummies, education (and experience), and a dummy variable for immigrant women interacted with the year effects. The results are displayed in Figures 2 and $3^{7}$.

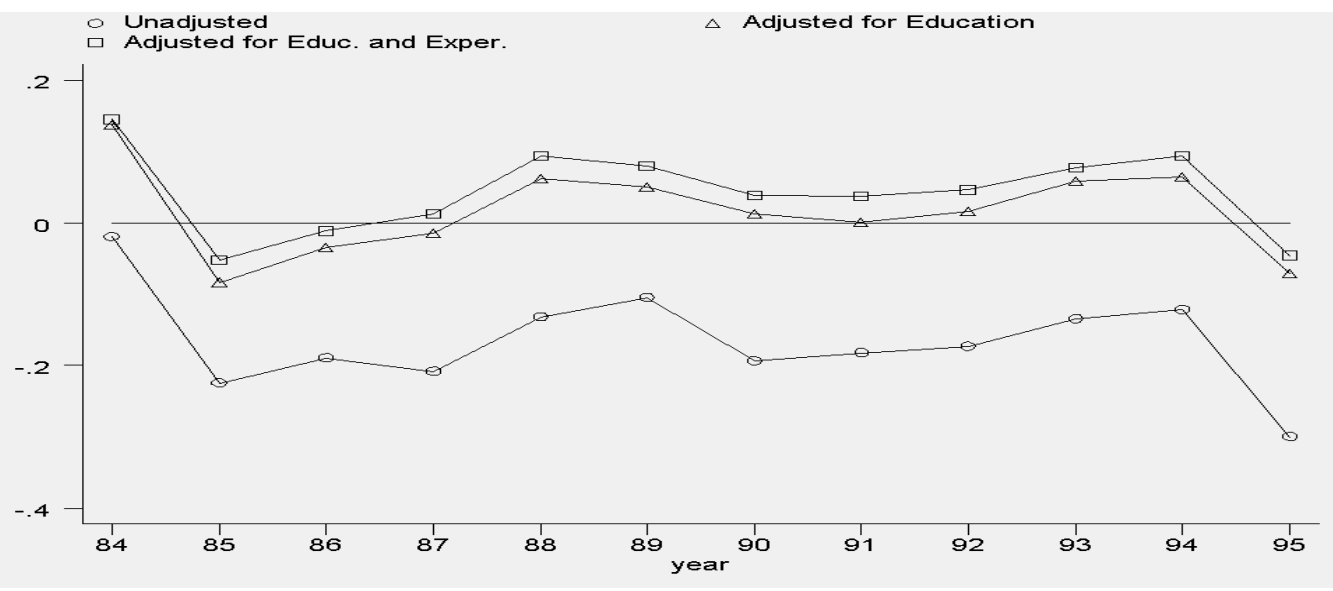

Figure 2: Wage Differences, Part-time Jobs, Natives and Migrants

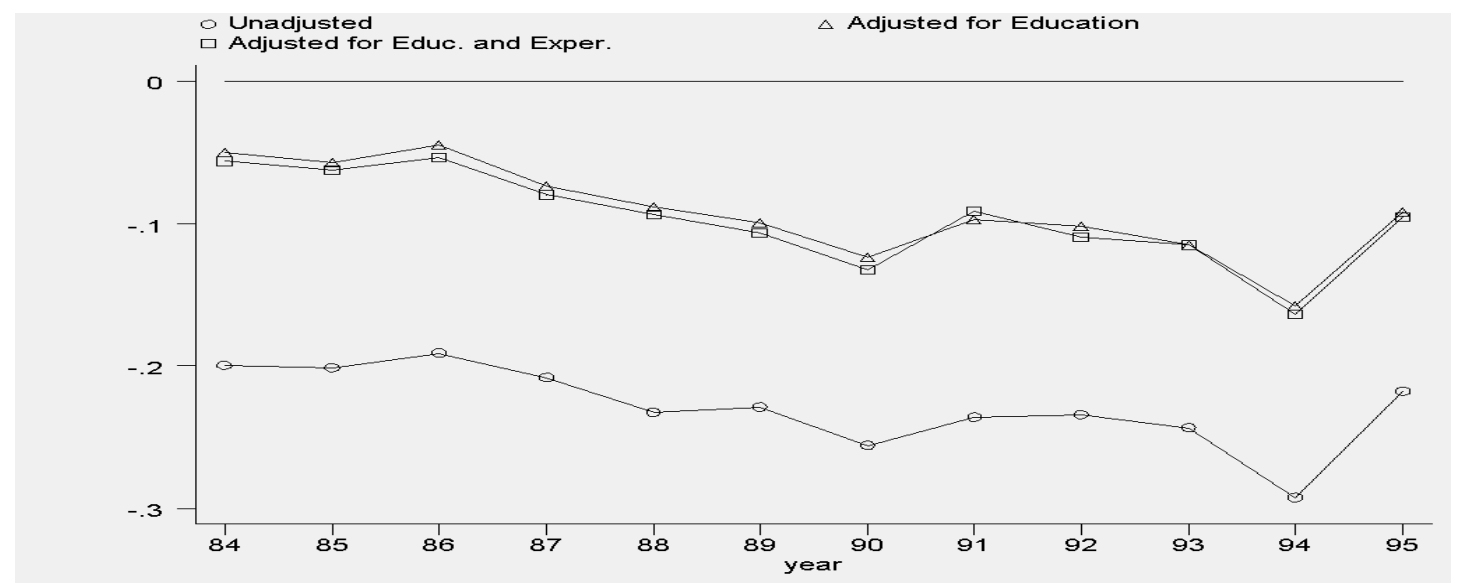

Figure 3: Wage Differences, Full-Time Jobs, Natives and Migrants

The figures indicate that much of the raw wage difference between native and

${ }^{7}$ Table A3 in the appendix reports coefficients for the interaction of unrestricted year effects and the indicator variable for foreign-born workers in regressions including year dummies. 
foreign-born women is due to educational differences. In fact, controlling for education eliminates the wage differential for part-time workers; for full-time workers, the differential reduces considerably, but remains significant (with an average wage disadvantage of about 9 percentage points). Finally, the inclusion of years of work experience has no significant effect on the wage differentials.

The estimated models do not take account of individual-specific effects, nor do they adjust for sample selection. They also impose the same parameters for migrants and natives. They do, however, indicate some significant differences between full- and parttime jobs for the two populations. The next section presents more structural models, which are estimated separately for the two populations.

\section{Participation Behaviour}

We commence our econometric analysis with an analysis of labour force participation. Tables 2 and 3 report marginal effects of our selection model with incidental thresholds, together with their standard errors. All effects are evaluated for an individual with average sample characteristics. In Table 2, we present results in columns 1 (natives) and 3 (migrants) which do not condition on individual-specific effects, whereas those in columns 2 and 4 do so. In all estimations, we allow for time effects in the wage equations, the participation equation, and the parameterisation of the incidental threshold parameter. Furthermore, we allow the variances of wages in the two sectors to vary over time, and we do not impose time constancy on the correlation coefficients between 
selection- and wage equations ${ }^{8}$.

In the last rows of Table 2 we present specification tests, imposing zero restrictions on various sets of parameters. The differences in the distance statistics between the restricted and unrestricted model is $\chi^{2}$ distributed, with degrees of freedom equal to the additional number of restrictions. We report the distance statistics, as well as the corresponding p-values. For both migrants and natives, we reject the null hypothesis of non-correlated fixed effects in the participation equation. We do not reject noncorrelated fixed effects in the wage equations, but we reject non-correlated fixed effects for the overall model (both conditional on sample selection). Finally, we reject the hypothesis of no sample selection for both migrants and natives. Accordingly, allowing for sample selection and fixed (correlated) individual effects seems important for our specific application.

In both samples, the effect of the children variables and of other household income decrease in absolute size when controlling for fixed effects. This indicates that unobserved factors which positively affect participation are negatively correlated with the number of children in the various categories, and with other household income. The reductions are however modest. In the following discussion, we refer to columns 2 and 4, which take account of fixed effects in the way specified above. Children exert a negative impact on participation probabilities in both sectors. For natives, an additional child in the age category 0-5 reduces the participation probability in part-time jobs by 40 percentage points on average, and by 43 percentage points in full-time jobs. The effect of children in the age category 6 and older is more modest, and larger for

\footnotetext{
${ }^{8}$ Imposing equality on the variances of wages over time was rejected for both native and foreign born women. Also, imposing equality on the correlation coefficients was rejected for both populations.
} 
Table 2: Labour Force Participation, Ordered Models, Minimum Distance Results

\begin{tabular}{lcccccccc}
\hline \hline & \multicolumn{3}{c}{ Natives } & \multicolumn{3}{c}{ Migrants } \\
Part-Time & \multicolumn{2}{c}{$\mathbf{1}$} & \multicolumn{2}{c}{$\mathbf{2}$} & \multicolumn{3}{c}{$\mathbf{3}$} & \multicolumn{4}{c}{} \\
& No Indiv. Effects & \multicolumn{2}{c}{ Indiv.Effects } & No Indiv. Effects & \multicolumn{2}{c}{ Indiv.Effects } \\
& Marg. & Std. & Marg. & Std. & Marg. & Std. & Marg. & Std. \\
& Effects & Errors & Effects & Errors & Effects & Errors & Effects & Errors \\
\hline Age/10 & 0.877 & 0.082 & 0.806 & 0.085 & 0.487 & 0.095 & 0.403 & 0.100 \\
Age $^{2} / 100$ & -1.301 & 0.095 & -1.230 & 0.099 & -0.672 & 0.111 & -0.592 & 0.116 \\
Education/10 & 0.475 & 0.038 & 0.512 & 0.038 & 0.312 & 0.046 & 0.309 & 0.047 \\
\# children age $\leq 5$ & -0.436 & 0.016 & -0.401 & 0.024 & -0.242 & 0.019 & -0.169 & 0.029 \\
\# children age $>5$ & -0.137 & 0.010 & -0.130 & 0.016 & -0.057 & 0.009 & -0.023 & 0.015 \\
Hh.income/1000 & -1.012 & 0.047 & -0.608 & 0.076 & -0.952 & 0.063 & -0.416 & 0.094
\end{tabular}

Full-Time

\begin{tabular}{|c|c|c|c|c|c|c|c|c|}
\hline Age/10 & 0.525 & 0.057 & 0.457 & 0.059 & 0.751 & 0.130 & 0.592 & 0.129 \\
\hline $\operatorname{Age}^{2} / 100$ & -0.925 & 0.068 & -0.852 & 0.071 & -1.037 & 0.153 & -0.874 & 0.151 \\
\hline Education/10 & 0.494 & 0.029 & 0.528 & 0.030 & 0.508 & 0.067 & 0.464 & 0.068 \\
\hline$\#$ children age $\leq 5$ & -0.502 & 0.015 & -0.432 & 0.022 & -0.410 & 0.027 & -0.242 & 0.041 \\
\hline$\#$ children age $>5$ & -0.224 & 0.008 & -0.189 & 0.014 & -0.136 & 0.014 & -0.048 & 0.022 \\
\hline Hh.income/1000 & -1.159 & 0.037 & -0.598 & 0.056 & -1.834 & 0.075 & -0.777 & 0.110 \\
\hline Observations & \multicolumn{4}{|c|}{16655} & \multicolumn{4}{|c|}{6789} \\
\hline
\end{tabular}

\section{Specification Tests}

Corr. fixed effects

$$
\begin{array}{cll}
\text { participation } & \chi^{2}(6)=231 ; \mathrm{p} \text {-value }=0.000 & \chi^{2}(6)=143.22 ; \mathrm{p} \text {-value }=0.000 \\
\text { wages } & \chi^{2}(4)=6.09 ; \mathrm{p} \text {-value }=0.192 & \chi^{2}(4)=6.33 ; \mathrm{p} \text {-value }=0.175 \\
\text { both } & \chi^{2}(10)=237.49 ; \mathrm{p} \text {-value }=0.000 & \chi^{2}(10)=151.28 ; \mathrm{p} \text {-value }=0.000 \\
\text { Sample selection } & \chi^{2}(24)=87.83 ; \mathrm{p} \text {-value }=0.000 & \chi^{2}(24)=36.95 ; \mathrm{p} \text {-value }=0.044 \\
\hline
\end{array}
$$

Note: All specifications include year dummies. 
full-time than for part-time jobs.

Compare these results to migrants (column 4). Here the effect of children is far less dramatic - in the age group 0-5, an additional child reduces the participation probability by 17 percentage points in part-time jobs and 24 percentage points in fulltime jobs. The negative effect of children in the age group above 5 years is considerably smaller than for natives, and not significant for part-time jobs. All the native-migrant differences in point estimates are significant. These results are compatible with the idea that migrants rely on more family support, providing child care and reducing the wife's reservation wage. This conclusion is perfectly consistent with the findings of DuLEEP and SANDERS (1993). In the aggregate, the depressing effect of young children on the labour force participation behaviour of native women tends to be compensated by their lower fertility.

Education exerts a clear positive impact on the labour force participation behaviour of both migrant and native women. For female natives, an additional year of education raises the probability to work either full-time or part-time by approximately five percentage points. The impact of an additional year of education on migrant women working full-time is of comparable magnitude. Only the effect of education on migrant women's propensity of working part-time is somewhat smaller, approximately at the order of three percentage points. In consequence, the lower educational endowments of migrant women tend to reduce the intensity of their labour force participation.

The effect of other household income is strongly significant for both populations, and for part- and full-time jobs, approximately implying a reduction of the participation propensity by five percentage points for an additional 100DM of household income. While for part-time jobs, migrants react less sensitively to increases in house- 
hold income, they react more elasticly for full-time jobs. In both cases however the differences to native women are not significant. In effect, the participation intensity of native women tends to be lower ceteris paribus due to the relatively high income of their husbands.

Since the effect of the age variables is difficult to interpret, we have plotted the participation-age profiles for both migrants and natives in Figure 4.
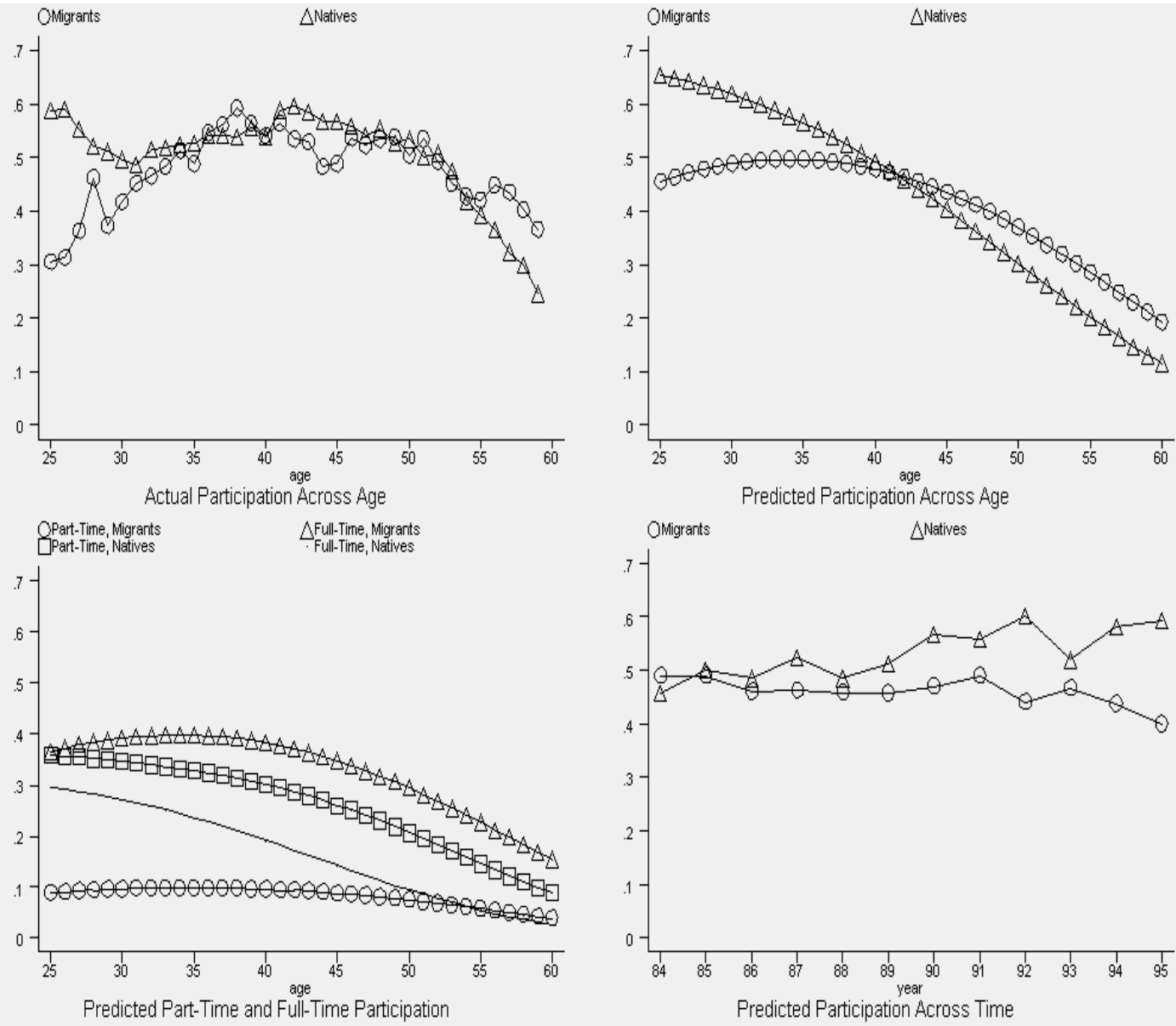

Figure 4: Participation Patterns Across Age and Time

The upper left panel displays the empirical participation probabilities between ages 
25 and 60 . The pattern is inverse $\mathrm{u}$-shaped for both migrants and natives, and except for young and old ages, it seems to be similar for the two groups. These numbers do not distinguish between life cycle effects on the one side, and age- and cohort effects on the other. The second upper panel presents the conditional age profile based on our estimation results, and evaluated at respective sample means ${ }^{9}$. These numbers reveal that at the beginning of the working cycle, participation probabilities are higher for natives; however, at around 40 years of age, this reverses.

The left lower panel breaks these figures down to part- and full-time participation probabilities. The probability of migrants to participate in full-time jobs is higher than that of natives throughout the entire age range. Natives are more likely to work in part-time jobs, and the age profile seems to be inverse U-shaped, while it is flat and slightly decreasing for migrants. Profiles converge towards the end of the career. Finally, the right lower panel reports the time effects, evaluated at the vector of average characteristics for the migrants and natives. Here the pattern is similar as in Figure 1 (note the different scales, though). The participation gap between natives and immigrants is increasing towards the end of the observation period. Accordingly, the notable divergence in aggregate participation probabilities after the early 1990's is genuine and should not be attributed to possible composition effects which might have been induced by distinct participation-age profiles.

\footnotetext{
${ }^{9}$ The probabilities are computed as $\Phi\left(-\bar{X}^{\prime} \hat{\xi}\right)$ (non-participation), $\Phi\left(\exp \left(\bar{X}^{\prime} \beta\right)-\bar{X}^{\prime} \hat{\xi}\right)-\Phi\left(-\bar{X}^{\prime} \hat{\xi}\right)$ (part-time) and $1-\Phi\left(\exp \left(\bar{X}^{\prime} \beta\right)-\bar{X}^{\prime} \hat{\xi}\right)$ (full-time), where the explanatory variables are evaluated at sample means. That is, the comparison is made for migrants and natives with identical observable characteristics. These probabilities are evaluated for all age categories between 25 and 60 .
} 


\subsection{Years of Residence and Return Plans}

We now investigate the participation behaviour of immigrants in more detail. The specification reported in column 1 of Table 3 adds the years of residence as additional regressor to the specification documented in the last column of Table 2. While the other coefficients are not changed markedly, the effect of duration of residence on participation probabilities is strong and clearly positive for both part-time and fulltime jobs, with a larger effect on full-time participation. In a second specification which is reported in column 2 of Table 3 we add the years since migration of the husband. By contrast to wife's duration of residence, this variable affects female participation probabilities in both segments negatively. These results are consistent with Chiswick (1980) and Duleep and SAnders (1993) who argue that the positive effect of women's own duration of residence reflects the growing applicability of host country-specific skills.

The negative effect of husband's duration of residence on female participation seems to confirm DuleEP and SANDER's (1993) argument that migrant women might be providing financial support initially, while their husband invest into host country-specific skills. An alternative explanation might be that this variable captures budget constraints. As our descpriptive results indicated, it is typical for labour migration that the husband arrives earlier, and the female partner follows after a stable job is found by the initial migrant. Conditional on the wife's years since migration, the husband's years since migration then simply picks up the effect of the difference in years since migration between husband and wife. If the husband arrives earlier, budgetary considerations may be less binding, and the female partner may abstain from labour force 
participation.

Not only the budgetary considerations associated with the timing of arrival may affect the behavioural pattern of a migrant family, but also the plans migrants make for a possible return to their home country. Following DuleEP and SANDERs (1993) one could argue that women who anticipate to live permanently in the host country exhibit a higher participation rate, because this intention enhances efforts to integrate in the new society. A simple life cycle model would predict the opposite, however. If expected future wages in the home country are lower than in the host country, the individual shifts demand for leisure from the present to the future, if she plans to return. This reduces the present reservation wage, and leads to increased participation probabilities (see Dustmann 1997, for details on this argument).

Consequently, the sign of variables which measure permanent settlement intentions is not clear ex ante. Since in migrant households the decision to return to the home country may be dominated by the husband, information on the husband's plans are likely to represent current return plans for the household, while a possibly diverging statement of the wife rather picks up her sentiment towards integration. Accordingly, if we had information on the husband's and the wife's intention to settle permanently, then we should expect a negative effect of the husband's intention to stay permanently on the wife's participation pattern, but, conditional on the husband's plans, a positive effect of the wife's desire to remain in the host country.

We are in the privileged position to have information about return plans of the migrant population in our sample. In each of the 12 waves, every individual born abroad has been asked whether he/she intends to remain permanently in Germany or not. We therefore observe return intentions for both husband and wife. Over the 
Table 3: Labour Force Participation of Migrants, Ordered Models, Minimum Distance Results

Part-Time

Marg.Eff. Std.Error Marg.Eff. Std.Error Marg.Eff.

Std.Error

\section{Individual Characteristics:}

Age/10

0.284

0.113

0.267

0.121

0.311

0.119

$\mathrm{Age}^{2} / 100$

$-0.508$

0.130

$-0.488$

0.139

$-0.548$

0.137

Education/10

0.259

0.052

0.280

0.056

0.276

0.056

\# children age $\leq 5$

$-0.170 \quad 0.034$

$-0.191$

0.036

$-0.173$

0.035

\# children age $>5$

-0.016 0.018

$-0.022$

0.019

$-0.017$

0.018

Hh.income/10000

$-0.420 \quad 0.111$

$-0.414$

0.118

$-0.486$

0.116

Yrs.residence/10

$0.239 \quad 0.021$

0.313

0.025

0.258

0.023

Yrs.res.husb./10

$-0.119 \quad 0.024$

Intentions to Stay Permanently:

Wife

Husband

$\begin{array}{rr}0.100 & 0.036 \\ -0.118 & 0.035\end{array}$

Full-Time

Marg.Eff. Std.Error Marg.Eff. Std.Error Marg.Eff.

Std.Error

\section{Individual Characteristics:}

Age/10

0.491

0.138

0.492

0.137

0.516

0.140

$\mathrm{Age}^{2} / 100$

$-0.857$

0.161

$-0.819$

0.159

$-0.884$

0.164

Education/10

$0.394 \quad 0.072$

0.408

0.070

0.410

0.072

Num. children age $\leq 5$

$-0.235 \quad 0.0440$

$-0.221$

0.0462

$-0.228$

0.045

Num. children age $>5$

$-0.050$

0.023

$-0.043$

0.023

$-0.051$

0.023

Hh.income/10000

$-0.757$

0.116

$-0.725$

0.118

$-0.724$

0.116

Yrs.residence/10

$0.307 \quad 0.025$

0.367

0.031

0.307

0.026

Yrs.res.husb./10

$-0.206$

0.030

Intentions to Stay Permanently:

Wife

Husband

$-$

0.045

0.047

$-0.131$

0.047

\footnotetext{
Note: All specifications include year dummies and individual-specific effects. 6431 Observations.
} 
entire panel, in 30 percent of the responses, the husband replied that he would like to return; the percentage for the female partner is the same. However, in 7 percent of the responses, the husband intended to return, but the wife intended to stay, while in 6.5 percent of the responses, the opposite was the case.

In column 3 we have included indicator variables which are equal to one if the wife or the husband intend to remain permanently, respectively. The coefficient estimates demonstrate that a permanent intention of the husband has clearly a negative and significant effect on participation in both segments. These results are compatible with intertemporal substitution of labour supply. Conditional on the male's intention, the female's intention to remain permanently increases her participation probability in both sectors. This effect is less precisely estimated for full time workers. Thus, our results are compatible with both hypotheses. An intertemporal substitution effect seems to be present, but there is also some evidence that permanent settlement intentions of the wife influence her labour supply along the lines suggested in the literature.

\section{$5 \quad$ Wages of Migrants and Natives}

We now turn to an analysis of wages. Table 4 presents wage regressions for migrants and natives. All regressions take account of selection by estimating the selection equation simultaneously with the wage equations. In addition to non-linearity, the wage equations are identified by excluding variables on the number of children in the two age categories, as well as other household income. Furthermore, while we condition on total actual labour market experience in the wage equations, we condition on age in the participation equation instead. When we add additional variables to the wage 
equation, we add the same regressors to the participation equation.

Columns 1 (natives) and 3 (migrants) do not control for individual-specific effects, while the other specifications incorporate them. Generally, the effect of education is to substantially raise wages for native women. Native women in part-time work experience an increase of over 10 percent in their wages for each additional year of schooling, while those in full-time employment receive a slightly smaller return to additional schooling. By contrast, our results indicate that female migrants experience no return to schooling when working part-time, and the return in full-time work is modest. This is not altogether unexpected, since many individuals in the foreign population have received their education in their home countries, and it may not be completely transferable to the host country.

Comparing the coefficients on the experience variables between columns 1 and 2 (or 3 and 4 for migrants) reveals that upon controlling for unobserved heterogeneity the effect of experience decreases for both migrants and natives in full-time employment. While it remains the same for natives in part-time employment, it also decreases for migrants in part-time employment. These results suggest that typically, individuals with a high unobserved productivity component $\alpha_{i}$ are likely to have a stronger labour force attachment, and, therefore, display higher levels of experience, leading to upward biased estimates of work history variables in columns 1 and 3 .

Overall, the results in columns 2 and 4 indicate that native women are rewarded by wage increases for the accumulation of work experience in both full-time and part-time jobs. While the experience-wage profile peaks at approximately 30 years for full-time jobs, the results imply that experience exerts a steadily rising impact on part-time wages throughout the working career. On the other hand, wage-experience profiles 
Table 4: Wage Equations, Natives and Migrants

\begin{tabular}{|c|c|c|c|c|c|c|c|c|}
\hline \multirow{5}{*}{ Part-Time } & \multicolumn{4}{|c|}{ Natives } & \multicolumn{4}{|c|}{ Migrants } \\
\hline & \multicolumn{2}{|c|}{1} & \multicolumn{2}{|c|}{2} & \multicolumn{2}{|c|}{3} & \multicolumn{2}{|c|}{4} \\
\hline & \multicolumn{2}{|c|}{ No Indiv. Effects } & \multicolumn{2}{|c|}{ Indiv.Effects } & \multicolumn{2}{|c|}{ No Indiv. Effects } & \multicolumn{2}{|c|}{ Indiv.Effects } \\
\hline & \multicolumn{2}{|r|}{ Std. } & \multicolumn{2}{|r|}{ Std. } & \multicolumn{2}{|r|}{ Std. } & \multicolumn{2}{|r|}{ Std. } \\
\hline & Coeff. & Errors & Coeff. & Errors & Coeff. & Errors & Coeff. & Errors \\
\hline Education/10 & 1.155 & 0.032 & 1.155 & 0.032 & 0.050 & 0.080 & -0.016 & 0.076 \\
\hline Experience/10 & 0.177 & 0.026 & 0.181 & 0.070 & 0.132 & 0.061 & 0.055 & 0.203 \\
\hline Exp. $^{2} / 100$ & -0.026 & 0.006 & -0.012 & 0.015 & -0.031 & 0.017 & 0.006 & 0.044 \\
\hline Pred. Log Wage (1984)* & \multicolumn{2}{|c|}{2.17} & \multicolumn{2}{|c|}{2.17} & \multicolumn{2}{|c|}{2.42} & \multicolumn{2}{|c|}{2.35} \\
\hline Pred. Log Wage $(1984)^{* *}$ & \multicolumn{2}{|c|}{2.32} & \multicolumn{2}{|c|}{2.33} & \multicolumn{2}{|c|}{2.39} & \multicolumn{2}{|c|}{2.41} \\
\hline Observations & \multicolumn{4}{|c|}{4140} & \multicolumn{4}{|c|}{706} \\
\hline \multicolumn{9}{|l|}{ Full-Time } \\
\hline Education/10 & 0.834 & 0.023 & 0.842 & 0.022 & 0.350 & 0.024 & 0.342 & 0.024 \\
\hline Experience/10 & 0.241 & 0.018 & 0.147 & 0.060 & 0.105 & 0.020 & 0.067 & 0.065 \\
\hline Exp. $^{2} / 100$ & -0.044 & 0.004 & -0.025 & 0.012 & -0.012 & 0.005 & -0.019 & 0.013 \\
\hline Pred. Log Wage (1984)* & \multicolumn{2}{|c|}{2.28} & \multicolumn{2}{|c|}{2.29} & \multicolumn{2}{|c|}{2.25} & \multicolumn{2}{|c|}{2.25} \\
\hline Pred. Log Wage $(1984)^{* *}$ & \multicolumn{2}{|c|}{2.48} & \multicolumn{2}{|c|}{2.41} & \multicolumn{2}{|c|}{2.35} & \multicolumn{2}{|c|}{2.29} \\
\hline Observations & \multicolumn{4}{|c|}{3502} & \multicolumn{4}{|c|}{2424} \\
\hline
\end{tabular}

Note: All specification include time effects and control for selection.

*: Evaluated at 0 years of Experience and 10 years of Education.

*: Evaluated at 10 years of Experience and 10 years of Education. 
of immigrant workers (conditional on unobserved heterogeneity) are entirely flat in both sectors. For migrant women there hardly seems to be any wage growth as they accumulate more work experience. These results are compatible with immigrants being employed in low quality jobs which do not allow for noticeable wage mobility, and only require low levels of human capital (like cleaning jobs, low level service jobs etc.).

In the last two rows of the table, we display predicted wages in the respective sector for 10 years of education, and for 0 and 10 years of labour market experience, evaluated in 1984 for migrants and natives. For both part-time and full-time jobs, and for the specifications with and without individual heterogeneity, the steeper experienceearnings profile of natives is reflected in higher predicted wage growth over the first 10 years of the career. This growth tends to be less pronounced in the estimates including individual-specific effects. In the further discussion, we concentrate on the predicted wage after 10 years of work experience. The figures for native women confirm the distinction of low part-time wages and high full-time wages typically emphasized in the literature (e.g. ERmisch and Wright 1993 or Averett and Hotchkiss 1997). Yet, the entries for female migrants suggest that they would perform comparatively well in part-time jobs - to a large extent, however, this is a reflection of sampling variation, expressing atypically favourable average wages of migrant part-time workers in 1984.

During the 1980s and 1990s the position of workers in the lower tiers of the income distribution has deteriorated in most parts of the world, most visibly in the US and the UK, but to some degree in all advanced economies (see e.g. LEVY and Murnane 1992). We therefore have to ask how much the relative wages of migrant women have been declining over the sample period; entries in Table 4 refer to the initial period, 
1984, and to the effects of education and experience whose impact has been restricted to be constant across periods in the estimation. In Figure 5, we have plotted the development of predicted wages for typical migrants and natives in both full-time and part-time jobs, normalized to the initial observation period ${ }^{10}$. These entries therefore represent aggregate wages, after netting out wage growth due to change in educational endowments, to the differential accumulation of labour market experience and the effects of selection.

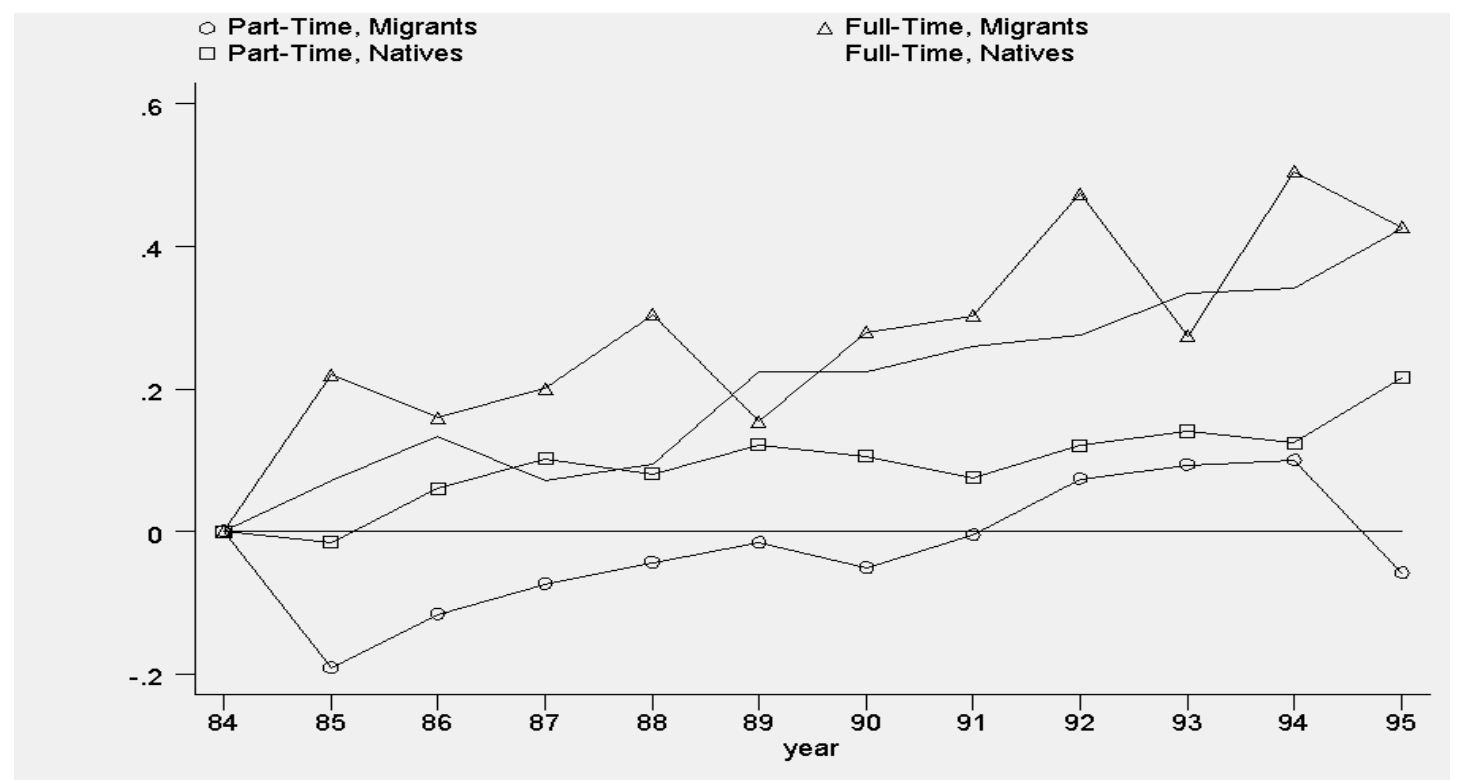

Figure 5: The Development of Predicted Log Wages

The figure indicates quite a dramatic growth in wages in full-time jobs for both native and migrant women. By contrast, real wages in part-time jobs - which were lower than full-time wages to begin with - fluctuate somewhat but do not change dramatically over the observation period. A 95\% confidence interval around part-time

\footnotetext{
${ }^{10}$ These graphs are based on the wage equations in columns 2 and 4 of Table 4.
} 
wages includes zero for all years, but the last for native workers. This general pattern is in accordance with an overall trend to a deteriorating wage position of workers in menial jobs. Growth in full-time wages is slightly higher for migrant women, leading to a very moderate convergence between the wages of migrant and native full-time women which is felt throughout the period. Similarly, after a downward correction of the real wages of migrant part-time women after the atypical 1984 values, immigrant women on part-time jobs experience a slightly larger wage growth than native women, up until 1994, including the short boom period following German re-unification. The downturn of migrants' wages at the end of the sample period is consistent with our observations on labour force participation - the early- to mid-1990s were characterized by a severe recession, and migrant part-time, and to somewhat a lesser extent, full-time workers seem to have suffered disproportionately.

\subsection{Assimilation and Return Intentions}

In Table 5 we follow the literature on immigrant assimilation, and include the number of years of residence in the host country, and several other variables capturing the respondents' immigration history as additional regressors. Particularly for the duration of residence, it has frequently been argued that it measures the extent to which immigrants accumulate skills specific to the host country labour market (see the seminal

paper by Chiswick 1978, Borjas 1987, Borjas 1991, Borjas 1994). Previous empirical literature on female migrants' wages has in fact produced contradictory results about the effect of this variable. LONG (1980), for instance, finds that the effect on wage earnings is negative; he explains this by the wife supporting the family unit at the start of the migration history, while the husband invests into country-specific 
skills. Other authors (CHISWICK 1980, BLAU 1980established positive effects of this variable on wages, though.

The solution of this puzzle may lie in the way the underlying participation process is taken into account, and in the distinction between part-time and full-time jobs. We have estimated the wage equation using pooled OLS estimation (including time dummies) for the entire sample. This specification is similar to those estimated in the literature. Similar to Long (1980), the wage effect of the duration residence is negative, albeit insignificant. When estimating the wage equation separately for full- and part-time workers, the results change dramatically. The effect on part-time workers is significant and negative (approximately 2 percent per year of residence), but positive and significant for full-time workers (nearly 0.5 percent per year). This result emphasizes the importance of distinguishing between full- and part-time jobs when analysing the wages of immigrant females. Results correcting for selectivity and unobserved heterogeneity in addition are similar, and reported in column 1 of Table 5.

Labour force participation and human capital accumulation of migrant couples may interact in quite particular ways. DuleEP and SANDERS (1993), for instance, find that husbands' duration of residence is negatively related to their wives' participation which is also demonstrated by our results. One explanation we gave for this finding is that if the wife arrives later, the husband may have accumulated sufficient resources; this allows the migrant family unit to adopt a more traditional pattern of labour market behaviour, with the wife abstaining from labour force participation. This may also affect the human capital accumulation of the wife in the labour market: if participating, these women may have lower incentives to invest in human capital.

In column 2 of Table 5, we add two dummy variables to the basic specification, 
Table 5: Wage Equations, Migrants

\begin{tabular}{|c|c|c|c|c|c|c|c|c|}
\hline \multirow[t]{2}{*}{ Part-Time } & \multicolumn{3}{|c|}{ Std. } & \multirow{2}{*}{$\begin{array}{l}\text { Std. } \\
\text { Errors }\end{array}$} & \multicolumn{3}{|c|}{ Std. } & \multirow{2}{*}{$\begin{array}{c}\text { Std. } \\
\text { Errors }\end{array}$} \\
\hline & Coeff. & Errors & Coeff. & & Coeff. & Errors & Coeff. & \\
\hline Education/10 & 0.056 & 0.072 & 0.069 & 0.072 & 0.092 & 0.072 & 0.056 & 0.071 \\
\hline Experience/10 & -0.023 & 0.192 & -0.063 & 0.187 & -0.011 & 0.186 & 0.023 & 0.187 \\
\hline Exp. ${ }^{2} / 100$ & 0.025 & 0.042 & 0.026 & 0.040 & 0.025 & 0.040 & 0.039 & 0.040 \\
\hline Yrs.Residence/10 & -0.201 & 0.031 & -0.187 & 0.032 & -0.179 & 0.041 & -0.206 & 0.030 \\
\hline
\end{tabular}

Timing of Immigration - Who Arrived First, Interaction Terms:

Wife

$-0.056 \quad 0.052$

Int.:Yrs.Res./10

Husband

Int.:Yrs.Res./10

Intentions to Stay Permanently:

Wife

$-0.047 \quad 0.036$

$\begin{array}{lllll}\text { Full-Time } & \text { Std. } & \text { Std. } & \text { Std. }\end{array}$

\begin{tabular}{lcccccccc} 
& Coeff. & Errors & Coeff. & Errors & Coeff. & Errors & Coeff. & Errors \\
\hline Education/10 & 0.353 & 0.024 & 0.341 & 0.024 & 0.340 & 0.025 & 0.364 & 0.337 \\
Experience/10 & 0.113 & 0.070 & 0.134 & 0.070 & 0.133 & 0.070 & 0.113 & 0.199 \\
Exp. $^{2} / 100$ & -0.025 & 0.014 & -0.029 & 0.014 & -0.029 & 0.014 & -0.026 & -0.026 \\
Yrs.Residence/10 & 0.042 & 0.013 & 0.040 & 0.013 & 0.035 & 0.014 & 0.045 & 0.030
\end{tabular}

Timing of Immigration - Who Arrived First, Interaction Terms:

Wife

$0.051 \quad 0.018$

Int.:Yrs.Res./10

Husband

Int.:Yrs.Res./10

$\begin{array}{llll}-\quad & - & 0.030 & 0.009\end{array}$

Intentions to Stay Permanently:

Wife $-0.004 \quad 0.013$

$-0.003 \quad 0.007$

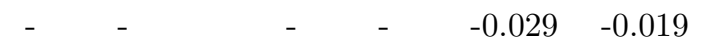

Note: All equations include time dummies and individual-specific effects; 663 (part-time) and 2298 (full-time) observations. All specifications control for selection. 
being equal to one if the husband arrived before the wife, and if the husband arrived later than the wife, respectively. The reference category for both indicators are women who arrived together with their husbands. In column 3 , these indicators are interacted with the duration of residence of the wife. It turns out that neither the coefficients of the indicator variables nor their interactions with years since migration are significant for part-time work. For full-time work, though, an earlier arrival of the wife leads to a 5 percent increase in wages, as compared to couples who arrived at the same time. Interacting this variable with the number of years of residence of the wife reveals that each year of residence increase wages by 0.3 percentage points more if the wife arrived earlier. The point estimate on the duration of residence is hardly changed by the inclusion of these additional regressors. The data thus yield some evidence for a differential effect of the timing of immigration.

Finally, we have investigated in more detail the role of return intentions on the wages of female immigrants. In the last column of Table 5, we have included as an additional regressor the indicator variable taking the value of one for those respondents who intend to stay permanently in the host country. The estimated coefficient for this variable is insignificant, and the estimated wage effect of the duration of residence on part-time wages is virtually unchanged. The estimated impact on full-time wages of years since migration becomes insignificant in this augmented specification. Overall, we can conclude that the particular immigration history of immigrant women as well as intentions regarding their future exert an effect on their wages, albeit with different implications for part-time and full-time workers. 


\section{Discussion and Conclusion}

In this paper, we analyse and compare wages and participation behaviour of immigrant and native women, using panel data over a 12 years period. The panel structure of our data allows us to control for individual-specific fixed effects which may be correlated with some of the model regressors. Moreover, we distinguish between part-time and full-time jobs. Specifically, the estimated selection models allow for non-random selection into these two types of jobs. Over the sample period, we observe that participation patterns of migrant and native females are similar initially; then they start to diverge, with migrant's participation probabilities declining. This decline coincides with a strong economic downturn in Germany, and is therefore consistent with migrants typically being allocated to more unstable jobs. In the analysis, we capture cyclical phenomena with a series of unrestricted year effects for both groups of female workers.

Overall, migrant and native women exhibit a very different propensity for participation in part-time and full-time jobs; while migrants predominantly work full-time, natives mainly work in part-time jobs. This pattern is stable over the sample period. We find that unconditional wages are always lower in part-time jobs; furthermore, migrants earn less in both labour market segments. Part of these differences is due to individual-specific characteristics: If we condition on education, the wage gap between migrant and native part-time wages disappears. For full-time wages, an unexplained and significant wage difference remains. Thus, in the aggregate immigrant women display a relatively favourable wage performance, with their large share of full-time jobs compensating somewhat for their relatively low wages.

We then estimate more structural models, confirming the perspective in the liter- 
ature that migrants' participation behaviour reacts less elastically to the number of children; however, it is similarly elastic to other household income for part-time jobs, and even more elastic for full-time jobs. Education increases participation probabilities of natives more than those of migrants in both segments, which is compatible with the view that migrant's educational achievements are only partly transferable to the host country, therefore decreasing their market wage relative to their reservation wage. Our analysis also suggests that an important determinant of immigrant participation behaviour is the particular immigration history - duration of residence in conjunction with the immigration history of the husband - and possible intentions to return to the country of origin in the future. Specifically, an intertemporal substitution effect seems to be present, but there is also some evidence that permanent settlement intentions of the wife influence her labour supply along the lines suggested in the literature.

In our analysis of wage equations, we find that the dramatic differences between the wages of female natives and migrants can be explained to a large extent by differences in observable characteristics, most prominently education. Moreover, the wages of native women tend to increase substantially as they accumulate work experience, with somewhat steeper experience-earnings profiles in full-time work, while those of immigrant women display no reaction to increasing work experience in either sector. Thus, in our sample of relatively experienced women, wage differences across groups are confirmed to mainly be a reflection of observable characteristics.

The distinction between part- and full-time wages reveals that native females face comparatively low wage offers in part-time jobs, unexplained by the principal observable characteristics relevant to productivity. Yet, we also find that they are frequently working part-time due to their particular family circumstances. These results confirm 
the earlier literature emphasizing a distinction of part- and full-time wages, suggesting that the lower part-time wage may reflect setup or training cost, but also the presence of monopsonistic elements in the market for part-time jobs. Migrant women, by contrast, mainly work full-time, and are less deterred to remain full-time workers in the presence of young children in the household. Their wages, although at a lower overall level, seem to be less affected by the choice of sector. This indicates that their larger flexibility in choosing between part-time and full-time jobs might lead to a lower differential between part-time and full-time wages, arguing for the presence of monopsonistic elements in the determination of the wages of female workers. 


\section{References}

Averett, Susan L. and Julia L. Hotchkiss (1997), Female Labor Supply With a Discontinuous Nonconvex Budget Constraint: Incorporation of a Part-time / Full-time Wage Differential, The Review of Economics and Statistics, 79, 461-470.

Blau, Francine (1980), Immigration and Labor Earnings in Early Twentieth Century America, in: Simon, Julian and Julie DaVanzo (Eds.), Research in Population Economics vol. 2, JAI Press, 21-41.

Borjas, George J. (1987), Self-Selection and the Earnings of Immigrants, American Economic Review, 77, 531-553.

Borjas, George J. (1991), Immigration and Self-Selection, in: Abowd, J. M. and Freeman, R. B. (EDs.) Immigration, Trade, and the Labor Market, Chicago: University of Chicago Press, 29-76.

Borjas, George J. (1994), The Economics of Immigration, Journal of Economic Literature, 32, 1667-1717.

Chamberlain, Gary (1984), Panel Data, in: Griliches, Zvi and Michael D. InTriligator (EDS.), Handbook of Econometrics, Volume II, ch. 22, Elsevier Science Publishers, 1247-1318.

Chiswick, BARry R. (1978), The Effect of Americanization on the Earnings of Foreign-Born Men, Journal of Political Economy, 86, 897-921.

Chiswick, Barry R. (1980), An Analysis of the Economic Progress and Impact of Immigrants, Washington D.C.

Duleep, Harriet Orcutt and Seth Sanders (1993), The Decision to Work By 
Married Immigrant Women, Industrial and Labor Relations Review, 46, 67-80.

Duleep, Harriet Orcutt and Seth Sanders (1994), Empirical Regularities Across Cultures: The Effect of Children on Woman's Work, Journal of Human Resources, 29, 328-347.

Duncan, Alan and Melvyn Weeks (1997) Behavioural Tax Microsimulation With Finite Hours Choices, European Economic Review, 41, 619-626.

Dustmann, Christian (1993), Earnings Adjustments of Temporary Migrants, Journal of Population Economics, 6, 153-168.

Dustmann, Christian (1997), Differences in the Labour Market Behaviour Between Temporary and Permanent Migrant Women, Labour Economics, 4, pp. 29-46.

Ermisch, John F. and Robert E. Wright (1993), Wage Offers and Full-time and Part-time Employment by British Women, The Journal of Human Resources, 28, 111-133.

Field-Hendrey, Elizabeth and Erol Balkan (1991), Earnings and Assimilation of Female Immigrants, Applied Economics, 23, 1665-1672.

Ilmakunnas, Seija and Stephen Pudney (1990), A Model of Female Labour Supply in the Presence of Hours Restrictions, Journal of Public Economics, 41, 183210.

Levy, Frank and Richard J. Murnane (1992), U.S. Earnings Levels and Earnings Inequality: A Review of Recent Trends and Proposed Explanations, Journal of Economic Literature, 30, 1333-1381.

Long, John (1980), The Effect of Americanization on Earnings: Some Evidence for Women, Journal of Political Economy, 88, 620-629. 
Mundlak, Y. (1978), On the Pooling of Time Series and Cross Section Data, Econometrica, 46, 69-85.

Nakamura, Alice and Masao Nakamura (1983), Part-time and Full-time Work Behaviour of Married Women: A Model With a Doubly Truncated Dependent Variable, Canadian Journal of Economics, 16, 229-257.

Pradhan, Menno and Arthur van Soest (1995), Formal and Informal Sector Employment in Urban Areas of Bolivia, Labour Economics, 2, 275-297.

Reimers, Cordelia W. (1983), Labor Market Discrimination Against Hispanic and Black Men, The Review of Economics and Statistics, 65, 570-579.

Reimers, Cordelia W. (1985), Cultural Differences in Labor Force Participation Among Married Women, American Economic Review, Papers and Proceedings, 251235.

Schmidt, Christoph M. (1997), Immigrant Performance in Germany: Labor Earnings of Ethnic German Migrants and Foreign Guest-Workers, The Quarterly Review of Economics and Finance, 37, 379-397.

Wooldridge, Jeffrey M. (1995), Selection Corrections for Panel Data Models under Conditional Mean Independence Assumptions, Journal of Econometrics, 68, $115-132$.

Zabalza, A., C. Pissarides and M. Barton (1980), Social Security and the Choice Between Full-Time Work, Part-time Work and Retirement, Journal of Public Economics, 14, 245-276.

Zimmermann, Klaus F. (1993), Labour Responses to Taxes and Benefits in Germany, in: Atkinson, A. B. and G. V.Mogensen (EDs.) Welfare and Work Incen- 
tives. A North European Perspective, Oxford: Clarendon Press, 192-240. 
Table A1: Observations, Labour Force Participation, and Valid Wage Responses

\begin{tabular}{ccccccc}
\hline \hline & \multicolumn{3}{c}{ Natives } & \multicolumn{3}{c}{ Migrants } \\
Year & Obs. & Participants & Wages Reported & Obs. & Participants & Wages Reported \\
\hline 1984 & 2170 & $45.2 \%$ & $86.2 \%$ & 894 & $47.0 \%$ & $91.7 \%$ \\
1985 & 1959 & $47.1 \%$ & $83.3 \%$ & 751 & $47.9 \%$ & $90.0 \%$ \\
1986 & 1724 & $43.6 \%$ & $88.2 \%$ & 660 & $45.0 \%$ & $91.9 \%$ \\
1987 & 1768 & $47.9 \%$ & $84.6 \%$ & 707 & $47.5 \%$ & $88.1 \%$ \\
1988 & 1625 & $48.6 \%$ & $82.6 \%$ & 644 & $47.2 \%$ & $89.5 \%$ \\
1989 & 1506 & $49.3 \%$ & $82.7 \%$ & 608 & $48.4 \%$ & $88.1 \%$ \\
1990 & 1398 & $52.7 \%$ & $81.0 \%$ & 581 & $51.1 \%$ & $84.8 \%$ \\
1991 & 1328 & $54.8 \%$ & $82.3 \%$ & 535 & $54.2 \%$ & $86.9 \%$ \\
1992 & 1259 & $55.8 \%$ & $85.9 \%$ & 498 & $50.8 \%$ & $89.3 \%$ \\
1993 & 1196 & $56.5 \%$ & $85.1 \%$ & 461 & $53.1 \%$ & $91.0 \%$ \\
1994 & 1135 & $54.7 \%$ & $86.8 \%$ & 435 & $49.9 \%$ & $91.7 \%$ \\
1995 & 1084 & $55.7 \%$ & $86.1 \%$ & 388 & $47.7 \%$ & $91.9 \%$ \\
\hline \hline
\end{tabular}

The percentage figures express the number of labour market participants as shares of all observations and the number of workers with valid wage responses as shares of all participants, respectively. 
Table A2: Frequency of Valid Responses in the GSOEP Panel

\begin{tabular}{lcrcrcr}
\hline \hline & \multicolumn{2}{c}{ All } & \multicolumn{3}{c}{ Natives } & \multicolumn{3}{c}{ Migrants } \\
Years & Observations & $\%$ & Observations & $\%$ & Observations & $\%$ \\
\hline 1 & 577 & $15.0 \%$ & 387 & $14.0 \%$ & 190 & $17.7 \%$ \\
2 & 395 & $10.3 \%$ & 297 & $10.7 \%$ & 98 & $9.1 \%$ \\
3 & 272 & $7.1 \%$ & 207 & $7.5 \%$ & 65 & $6.1 \%$ \\
4 & 265 & $6.9 \%$ & 207 & $7.5 \%$ & 58 & $5.4 \%$ \\
5 & 224 & $5.8 \%$ & 175 & $6.3 \%$ & 49 & $4.6 \%$ \\
6 & 233 & $6.1 \%$ & 171 & $6.2 \%$ & 62 & $5.8 \%$ \\
7 & 180 & $4.7 \%$ & 125 & $4.5 \%$ & 55 & $5.1 \%$ \\
8 & 181 & $4.7 \%$ & 129 & $4.7 \%$ & 52 & $4.9 \%$ \\
9 & 187 & $4.9 \%$ & 134 & $4.8 \%$ & 53 & $4.9 \%$ \\
10 & 218 & $5.7 \%$ & 152 & $5.5 \%$ & 66 & $6.2 \%$ \\
11 & 326 & $8.5 \%$ & 220 & $8.0 \%$ & 106 & $9.9 \%$ \\
12 & 783 & $20.4 \%$ & 564 & $20.4 \%$ & 219 & $20.4 \%$ \\
\hline Total & 3841 & $100.0 \%$ & 2768 & $100.0 \%$ & 1073 & $100.0 \%$ \\
\hline \hline
\end{tabular}


Table A3: Native-Migrant Wage Differentials, Pooled OLS Regressions

\begin{tabular}{|c|c|c|c|c|c|c|}
\hline \multirow[t]{2}{*}{ Part-Time } & \multicolumn{2}{|c|}{ No Add. Controls } & \multicolumn{2}{|c|}{ + Educ. \& Exp. } & \multicolumn{2}{|c|}{ + Yrs.Residence } \\
\hline & Differential & Std.Error & Differential & Std.Error & Differential & Std.Errol \\
\hline 1984 & 0.0197 & 0.0617 & -0.1379 & 0.0556 & -0.1451 & 0.0551 \\
\hline 1985 & 0.2247 & 0.0640 & 0.0836 & 0.0576 & 0.0517 & 0.0572 \\
\hline 1986 & 0.1898 & 0.0711 & 0.0347 & 0.0640 & 0.0115 & 0.0635 \\
\hline 1987 & 0.2082 & 0.0625 & 0.0139 & 0.0564 & -0.0127 & 0.0560 \\
\hline 1988 & 0.1320 & 0.0616 & -0.0623 & 0.0556 & -0.0939 & 0.0552 \\
\hline 1989 & 0.1049 & 0.0644 & -0.0506 & 0.0580 & -0.0802 & 0.0575 \\
\hline 1990 & 0.1936 & 0.0664 & -0.0129 & 0.0599 & -0.0386 & 0.0594 \\
\hline 1991 & 0.1825 & 0.0633 & -0.0015 & 0.0571 & -0.0373 & 0.0567 \\
\hline 1992 & 0.1736 & 0.0627 & -0.0163 & 0.0566 & -0.0466 & 0.0562 \\
\hline 1993 & 0.1344 & 0.0606 & -0.0586 & 0.0547 & -0.0772 & 0.0543 \\
\hline 1994 & 0.1220 & 0.0635 & -0.0647 & 0.0573 & -0.0938 & 0.0569 \\
\hline 1995 & 0.3001 & 0.0719 & 0.0714 & 0.0649 & 0.0460 & 0.0644 \\
\hline \multirow[t]{2}{*}{ Full-Time } & \multicolumn{2}{|c|}{ No Add. Controls } & \multicolumn{2}{|c|}{ + Educ. \& Exp. } & \multicolumn{2}{|c|}{ + Yrs.Residence } \\
\hline & Differential & Std.Error & Differential & Std.Error & Differential & Std.Errol \\
\hline 1984 & 0.1998 & 0.0243 & 0.0502 & 0.0225 & 0.0563 & 0.0221 \\
\hline 1985 & 0.2014 & 0.0261 & 0.0570 & 0.0242 & 0.0624 & 0.0236 \\
\hline 1986 & 0.1912 & 0.0278 & 0.0450 & 0.0257 & 0.0537 & 0.0251 \\
\hline 1987 & 0.2084 & 0.0274 & 0.0737 & 0.0253 & 0.0798 & 0.0247 \\
\hline 1988 & 0.2327 & 0.0292 & 0.0882 & 0.0269 & 0.0937 & 0.0263 \\
\hline 1989 & 0.2291 & 0.0300 & 0.0995 & 0.0276 & 0.1066 & 0.0269 \\
\hline 1990 & 0.2561 & 0.0304 & 0.1240 & 0.0280 & 0.1325 & 0.0274 \\
\hline 1991 & 0.2363 & 0.0310 & 0.0973 & 0.0286 & 0.0914 & 0.0280 \\
\hline 1992 & 0.2344 & 0.0326 & 0.1022 & 0.0300 & 0.1097 & 0.0293 \\
\hline 1993 & 0.2437 & 0.0334 & 0.1152 & 0.0307 & 0.1152 & 0.0300 \\
\hline 1994 & 0.2927 & 0.0354 & 0.1580 & 0.0326 & 0.1637 & 0.0318 \\
\hline 1995 & 0.2179 & 0.0369 & 0.0921 & 0.0339 & 0.0956 & 0.0331 \\
\hline
\end{tabular}

Table entries represent coefficients of an interaction (year * native) in regressions including year dummies. 